\title{
Candida albicans isolated from human fungaemia induces apoptosis in an experimental endocarditis model
}

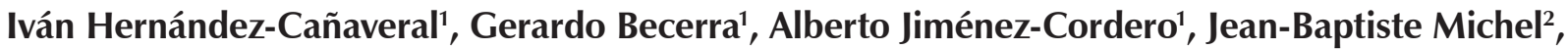 \\ Arturo Plascencia ${ }^{3}$, Miguel Domínguez-Hernández ${ }^{1 /+}$
'Departamento de Microbiología y Patología, Centro Universitario de Ciencias de la Salud, Universidad de Guadalajara, Jalisco, México ${ }^{2}$ INSERM U698, Cardiovascular Remodeling, Paris 7 University, Paris, France ${ }^{3}$ Servicio de Infectología Pediátrica, Hospital Civil Fray Antonio Alcalde, Guadalajara, Jalisco, México

Candida albicans is the most common fungal pathogen known to cause endovascular infections, such as vascular catheter sepsis, infections of vascular prostheses and infective endocarditis. A C. albicans isolate was used to determine the apoptotic potential of the fungus in a rat endocarditis model. This study confirms the ability of $\mathrm{C}$. albicans to induce apoptosis in myocardial tissue.

Key words: endocarditis - C. albicans - apoptosis

Infective endocarditis (IE) is a multifaceted disease that involves pathogen/host tissue interaction, leading to the formation of infected thrombotic vegetations (Durack \& Benson 1972). Outcomes and prognoses are influenced by host-related factors (demographics, comorbidities, predisposing conditions or procedures and affected valves), the causative pathogen and therapeutic intervention (medical or surgical) (Bonderman et al. 1999). Fungal endocarditis (FE) is an uncommon disease and while accounting for only $1.3-6 \%$ of all cases of infectious endocarditis, it carries a high mortality risk. Candida species are the most common agents involved in fungal endocarditis and as a result, Candida albicans is the most clinically important yeast isolated from patients suffering from FE (Pfaller \& Diekema 2007). $C$. albicans may cause endocarditis when it reaches the myocardial tissue by iatrogenic inoculation through contaminated plastic devices and fluids during continuous catheterisation (Scheld \& Sande 1995, Akpunonu et al. 2008). Several putative virulence factors of $C$. albicans have been identified, such as the ability to form germ tubes, adherence to host cells and secretion of proteinases (Hruskova-Heidingsfeldova 2008). Candida proteinases decrease the opsonic and bactericidal activities of human serum by degradation of the Fc portion of immunoglobulin $\mathrm{G}$ and proteolysis of the $\mathrm{C} 3$ component of the complement system (Kaminishi et al. 1995). Furthermore, the induction of programmed cell death or apoptosis by microorganisms may constitute an important step in pathogenesis (Park 2004).

\footnotetext{
Financial support: CONACYT (project 55295), ECOS-ANUIES Program, MO6-S02, PROMEP/103.5/07/2636

+Corresponding author: madh25@yahoo.com.mx

IHC and GB contributed equally to this work.

Received 6 February 2009

Accepted 8 July 2009
}

In mammals, apoptosis is a physiological mechanism of cell death that plays a key role in normal development (Majno \& Joris 1995). Cell death and ensuing changes in the secretion of cytokines may also play an important role in microbial pathogenesis (Hogan \& Basten 1988). Apoptosis has been demonstrated in several in vitro and in vivo studies (Zychlinsky et al. 1992, Gasparoto et al. 2004) of C. albicans infection (Majno \& Joris 1995, Renna et al. 2006) but not in experimental endocarditis.

The purpose of this study was to determine the ability of a $C$. albicans strain to induce apoptosis in myocardial tissue.

\section{MATERIALS AND METHODS}

Isolation of microorganisms and inoculum preparation - A C. albicans strain (HO7/116) obtained from a 10-month-old child admitted to the University Hospital Juan I. Menchaca in Guadalajara, Mexico, for neuroblastoma, fever and sepsis was used in this study. The strain, isolated from a culture of blood, was identified using an automated MicroScan device (Dade Behring, CA) and then confirmed by PCR in order to identify fungal ribosomal RNA of the yeast (Fujita et al. 2001). The isolate was subcultured on Sabouraud dextrose agar before use. Colonies were stored in liquid medium and the stock of the strain was kept at $-70^{\circ} \mathrm{C}$ in liquid medium supplemented with $10 \%$ glycerol (v/v).

To prepare inocula, fresh Candida cultures were grown and monitored by optical density (OD) measurements at a wavelength of $620 \mathrm{~nm}$ with a spectrophotometer (Jenway, Sacramento, CA). At an OD of 0.01, corresponding to $1.6 \times 10^{6}$ colony forming units $/ \mathrm{mL}$, samples were diluted in physiological saline (at $4^{\circ} \mathrm{C}$ ) before inoculation (Murray 2007).

Experimental endocarditis model - Female Wistar rats, 2-4 months old, were obtained from our animal care division and housed under 12:12 h light-dark cycles with access to water and rodent chow ad libitum. Sterile aortic vegetations were produced according to the classic model of Durack and Besson (Durack et al. 1973). In brief, a 
polyethylene catheter (PE10, Clay Adams) was connected to a manometer and inserted into the left ventricle through the right carotid artery, under ketamine-xylazine anaesthesia. The catheter remained indwelling throughout the experiment to induce thrombotic vegetation formation. Twenty-four hours after catheterisation, 20 rats were challenged intravenously with C. albicans inocula, in order to achieve fungal colonisation of the vegetation. Ten other rats were injected with sterile $0.9 \%$ saline. Additionally, 10 rats were sham operated to serve as controls.

Histology - Rats with sterile aortic vegetations were inoculated as described in the previous paragraph and sacrificed five days later. Representative samples of left endocarditis vegetations were excised and rapidly fixed in $10 \%$ neutral-buffered formol and processed using a routine paraffin inclusion technique for morphological analysis and immunohistochemistry. These samples included aortic tissue, aortic valves, left atria and left ventricles. Five-micron thick serial sections were stained with haematoxylin and eosin to identify cells and nuclei, Alcian blue coupled with nuclear red to reveal areas of mucoid accumulation (Okada \& Shozawa 1994) and their relation to cell nuclei and finally Schiff's periodic acid (PAS) to verify microbes in the vegetation.

Immunohistochemistry - To localise apoptotic cells, representative tissue sections from each group were analysed by terminal transferase-mediated dUTP nick end labelling (TUNEL) (Gavrieli et al. 1992). This method was used to visualise fragmented DNA on fixed sections according to the manufacturer's instructions (Roche). A positive control with DNase I (Qbiogene) treatment (3 U/ $\mathrm{mL}$ ) and a negative control omitting the use of terminal transferase were also performed. Cell nuclei were visualised by counterstaining with $100 \mathrm{ng} / \mathrm{mL}$ DAPI (4',6'diamidino-2-phenylindole hydrochloride).

Ethics - This study was approved by the Institutional Animal Care and Ethical Committee of the University of Guadalajara Health Sciences Center.

\section{RESULTS}

Each animal in which the catheter was correctly positioned within the ventricle developed aseptic or septic vegetations and cultures of all septic vegetations were positive for C. albicans.

Macroscopic evaluation upon sacrifice showed that vegetations were mainly localised on the aortic valves, but some were also observed on the aortic wall along the catheter trajectory (Fig. 1A) and in the left ventricle, in close contact with the catheter hole.

Microscopically, the vegetations were composed of red blood cells and neutrophils. In infected animals, invasion by $C$. albicans was observed in both vegetations and endocardial tissue, suggesting that fungal growth was rather similar at both sites. Yeast cells were readily identified by PAS staining and a large number of branching pseudohyphae were visible (inset; Fig. 1C). The vegetations had characteristics of platelet fibrin-rich clots, including a network of fibrin (by Mallory staining) (Fig. 2A). Alcian blue staining revealed the presence of large areas of mucoid substance in the valvular, aortic and myo-

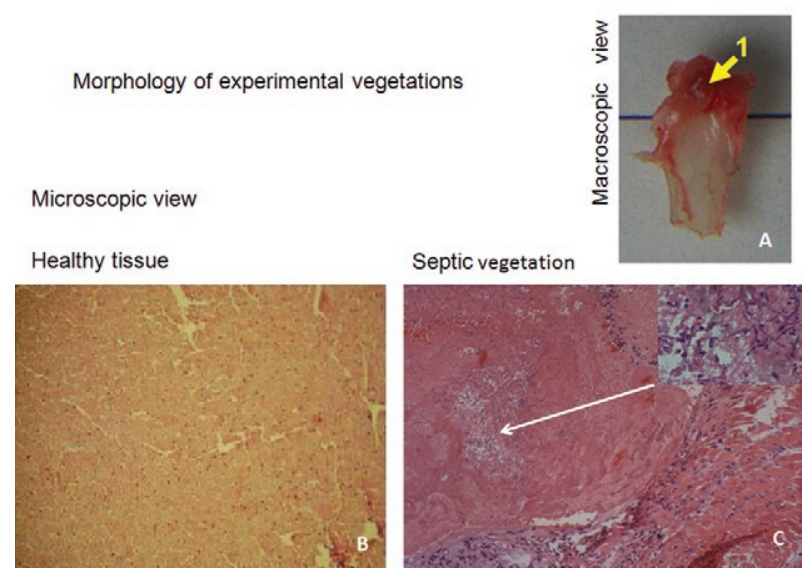

Fig. 1: morphology of aortic valve endocarditis. A: macroscopic view of the vegetation attached to the valve (arrow); B: a normal myocardial section is shown (hematoxylin-eosin, magnification 10X); C: microscopic view of a large septic vegetation attached to the aortic valve (hematoxylin-eosin, magnification 10X) with massive fungal pseudohyphal invasion and yeasts (inset, Grocott, 40X).


Fig. 2: sections of myocardial tissue and left ventricular septic vegetation. A: image corresponding to a zone of necrosis and fibrin deposition in myocardial tissue (arrow) (Mallory staining 40X); B: image showing mucoid degeneration in the aortic wall underlying the vegetation (Alcian blue, magnification $40 \mathrm{X}$ ). The border area of the myocardium beneath the vegetation exhibited the typical aspect of mucoid degeneration, including the accumulation of basophilic material associated with myocyte disappearance (arrow).

cardial tissue in close contact with the vegetations at the catheter hole (Fig. 2B). These mucoid areas were devoid of cell components, as demonstrated by nuclear red counterstaining. These areas were TUNEL-positive (Fig. 3A). In contrast, DAPI-positive cells were observed in both the myocardial area and the vegetation (Fig. 3B). Remarkably, the highest level of myocardial apoptosis was observed in animals exposed to infection stimuli. Only a few apoptotic cells were observed in myocardial sections from the catheter-induced thrombotic lesions without infection (Fig. 3C). Notably, there were no apoptotic cells in myocardial sections from sham-operated animals (Fig. 3D).

\section{DISCUSSION}

The incidence of invasive candidiasis has increased during the past few years (Hernandez-Hernandez 2003, Godoy et al. 2003, Colombo et al. 2006, Tortorano 2006). C. albicans is the most common fungal pathogen caus- 
ing endovascular infections, such as IE, vascular catheter sepsis and infections of vascular prostheses (Chang et al. 2008). Fungal infections have a low incidence in IE and several risk factors, such as injection drug abuse, immunosuppressive therapy, neutropaenia, malignancy and total parenteral nutrition (contamination) have been evoked (Filler \& Sheppard 2006, Utili et al. 2007).

Several studies have shown that $C$. albicans strains are increasingly expressing virulence traits such as proteinase production, adherence, resistance to antifungal drugs and phenotypic variation (Ghannoum \& Etteen 1986, Panagio et al. 2002). Moreover, C. albicans is able to induce membrane exposure of phosphatidylserine in murine macrophages (Panagio et al. 2002), thus suggest-
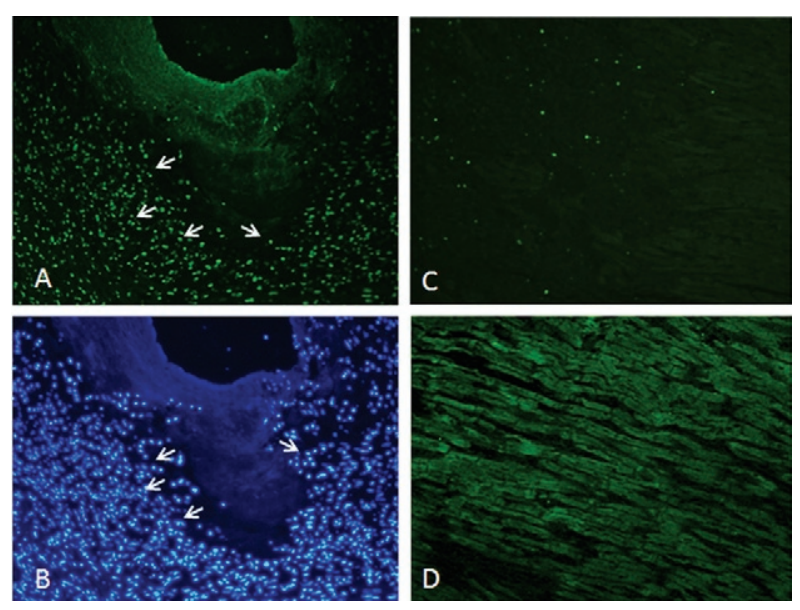

Fig. 3: myocardial apoptosis after Candida albicans infection. The assessment of apoptosis cells was performed in myocardium sections of all animals group (sham-operated, catheter-induced thrombotic lesions with and without infection). A: the detection of DNA fragmentation was performed using in situ terminal transferase-mediated dUTP nick end labelling (TUNEL) fluorescent method. TUNEL-positive cells are fluorescent green (arrows). Original magnification 40X; B: DAPI-positive nucleuses were present in the myocardium as well as in the vegetation; $\mathrm{C}$ : TUNEL assay performed on myocardial section from aseptic vegetation showed few apoptotic cells; D: section of myocardial tissue without apoptotic cells in a sham-operated rat.

ing apoptosis as a virulence mechanism. In the present study, a $C$. albicans strain isolated from a paediatric patient and identified by microbiological and molecular methods (data not shown) was successfully used to generate fungal endocarditis in the rat.

In agreement with a previous study (Rouzet et al. 2008) we observed some areas of mucoid degeneration and smooth muscle cell disappearance. Such basophilic areas corresponded to the accumulation of modified glycosaminoglycans. Mucoid degeneration appears to be linked to cell disappearance and matrix degradation (Bonderman et al. 1999). In bacterial endocarditis, this observation could be linked to the ability of proteases released by the septic vegetation to induce detachment and death of myocytes (Scheld \& Sande 1995). This proteolytic activity in the vicinity of the vegetation has two consequences. First, it promotes lysis of the vegetation itself and dissemination of the septic thrombus; second, it promotes degradation of the extracellular matrix and invasion of the underlying tissue, leading to valvular damage and/or abscess formation.

Secretion of aspartyl proteinases and serine proteases is considered to be an important virulence trait of C. albicans strains (dos Santos et al. 2006, Mohan \& Ballal 2008). In our study, using blotting and zymography experiments, we did not observe metalloproteases or serine proteases secreted by $C$. albicans to degrade the vegetation and underlying tissue (data not shown). However, we cannot rule out the possibility of the involvement of aspartyl proteinase activity of $C$. albicans in the observed matrix and tissue degradation.

In our experimental endocarditis model, TUNEL assays demonstrated myocardial apoptosis, as recently described (Rouzet et al. 2008). Apoptosis is a phenomenon closely related to the presence of some intrinsic host and yeast factors. TNF- $\alpha$ and nitric oxide are two molecules known to provoke cellular damage, DNA oxidative injury and apoptosis (Renna et al. 2006, Hosogi et al. 2008). Other factors from yeast, like phospholipomannan, an important molecular component of the cellular wall, play the role of adhesins and induce the production of cytokines like TNF- $\alpha$, thus likely stimulating apoptosis (Trinel et al. 1999). These molecules could be involved in the development of apoptosis. Further studies are needed to clarify this possibility in our endocarditis rat model.

\section{REFERENCES}

Akpunonu BE, Bittar S, Phinney RC, Taleb M 2008. Infective endocarditis and the new AHA guideline. Geriatrics 63: 12-19.

Bonderman D, Gharehbaghi-Schnell E, Wollenek G, Maurer G, Baumgartner H, Lang IM 1999. Mechanisms underlying aortic dilatation in congenital aortic valve malformation. Circulation 99: 2138-2143.

Chang A, Neofytos D, Horn D 2008. Candidemia in the 21st century. Future Microbiol 3: 463-472.

Colombo AL, Nucci M, Park BJ, Nouér SA, Arthington-Skaggs B, da Matta DA, Warnock D, Morgan J 2006. Epidemiology of candidemia in Brazil: a nation wide sentinel surveillance of candidemia in eleven medical centers. J Clin Microbiol 44: 2816-2823.

dos Santos AL, de Carvalho IM, da Silva BA, Portela MB, Alviano CS, de Araújo Soares RM 2006. Secretion of serine peptidase by a clinical strain of Candida albicans: influence of growth conditions and cleavage of human serum proteins and extracellular matrix components. FEMS Immunol Med Microbiol 46: 209-220.

Durack DT, Beeson PB 1972. Experimental bacterial endocarditis. I: Colonization of a sterile vegetation. Br J Exp Pathol 53: 44-49.

Durack DT, Beeson PB, Petersdorf RG 1973. Experimental bacterial endocarditis. 3. Production and progress of the disease in rabbits. Br J Exp Pathol 54: 142-151.

Filler SG, Sheppard DC 2006. Fungal invasion of normally nonphagocytic host cells. PLoS Pathog 2: e129.

Fujita SI, Senda Y, Nakaguchi S, Hashimoto T 2001. Multiplex PCR using internal transcribed spacer 1 and 2 regions for rapid detection and identification of yeast strains. J Clin Microbiol 39: 3617-3622. 
Gasparoto TH, Gaziri LC, Burger E, de Almeida RS, Felipe I 2004. Apoptosis of phagocytic cells induced by Candida albicans and production of IL-10. FEMS Immunol Med Microbiol 42: 219-224.

Gavrieli Y, Sherman Y, Ben-Sasson SA 1992. Identification of programmed cell death in situ via specific labeling of nuclear DNA fragmentation. J Cell Biol 119: 493-501.

Ghannoum M, Abu Elteen K 1986. Correlative relationship between proteinase production, adherence and pathogenicity of various strains of Candida albicans. J Med Vet Mycol 24: 407-413.

Godoy P, Tiraboschi IN, Severo LC, Bustamante B, Calvo B, Almeida LP, da Matta DA, Colombo AL 2003. Species distribution and antifungal susceptibility profile of Candida spp bloodstream isolates from latin american hospitals. Mem Inst Oswaldo Cruz 98: 401-405.

Hernandez-Hernandez F 2003. Frecuencia de micosis en pacientes inmunosuprimidos de un hospital regional de la Ciudad de México. Salud Publica Mex 45: 455-460.

Hogan PG, Basten A 1988. What are killer cells and what do they do? Blood Rev 2: 50-58.

Hosogi S, Iwasaki Y, Yamada T, Komatani-Tamiya N, Hiramatsu A, Kohno Y, Ueda M, Arimoto T, Marunaka Y 2008. Effect of inducible nitric oxide synthase on apoptosis in candida -induced acute lung injury. Biomed Res 29: 257-266.

Hruskova-Heidingsfeldova O 2008. Secreted proteins of Candida albicans. Front Biosci 13: 7227-7242.

Kaminishi H, Miyaguchi H, Tamaki T, Suenaga N, Hisamatsu M, Mihashi I, Matsumoto H, Maeda H, Hagihara Y 1995. Degradation of humoral host defense by Candida albicans proteinase. Infect Immun 63: 984-988.

Majno G, Joris I 1995. Apoptosis, oncosis and necrosis. An overview of cell death. Am J Pathol 146: 3-15.

Mohan das V, Ballal M 2008. M-proteinase and phospholipase activity as virulence factors in Candida species isolated from blood. Rev Iberoam Micol 25: 208-210.

Murray PR 2007. Manual of clinical microbiology, vol. II, ASM Press, Washington, $2256 \mathrm{pp}$.
Okada E, Shozawa T 1994. Mucoid degeneration of the atrioventricular valve caused by cardiac lymphostasis: an experimental study in dogs. Cardiovasc Pathol 3: 163-166.

Panagio LA, Felipe I, Vidotto MC, Gaziri LC 2002. Early membrane exposure of phosphatidylserine followed by late necrosis in murine macrophages induced by Candida albicans from an HIVinfected individual. J Med Microbiol 51: 929-936.

Park JB 2003. Phagocytosis induces superoxide formation and apoptosis in macrophages. Exp Mol Med 35: 325-335.

Pfaller MA, Diekema DJ 2007. Epidemiology of invasive candidiasis: a persistent public health problem. Clin Microbiol Rev 20: 133-163.

Renna MS, Correa SG, Porporatto C, Figueredo CM, Aoki MP, Paraje MG, Sotomayor CE 2006. Hepatocellular apoptosis during Candida albicans colonization: involvement of TNF- $\alpha$ and infiltrating Fas-L positive lymphocytes. Int Immunol 18: 1719-1728.

Rouzet F, Dominguez Hernandez M, Hervatin F, Sarda-Mantel L, Lefort A, Duval X, Louedec L, Fantin B, Le Guludec D, Michel JB 2008. Technetium $99 \mathrm{~m}$-labeled annexin V scintigraphy of platelet activation in vegetations of experimental endocarditis. Circulation 117: 781-789.

Scheld WM, Sande MA 1995. Endocarditis and intravascular infections. In GC Mandell, JE Bennet, R Dolin, Principles and practices of infectious diseases, Churchil Livingstone, New York, p. $740-782$.

Tortorano AM, Kibbler C, Peman J, Bernhardt H, Klingspor L, Grillot R 2006. Candidaemia in Europe: epidemiology and resistance. Int J Antimicrob Agents 27: 359-366.

Trinel PA, Plancke Y, Gerold P, Jouault T, Delplace F, Schwarz RT, Strecker G, Poulain D 1999. The Candida albicans phospholipomannan is a family of glycolipids presenting phosphoinositolmannosides with long linear chains of b-1,2-linked mannose residues. J Biol Chem 12: 30520-30526.

Utili R, Durante-Mangoni E, Tripodi MF 2007. Infection of intravascular prostheses: how to treat other than surgery. Int J Antimicrob Agents 30: 42-50.

Zychlinsky A, Prevost MC, Sansonetti PJ 1992. Shigella flexneri induces apoptosis in infected macrophages. Nature 358: 167-169. 